\title{
A POETICIDADE DA IMAGEM NO FILME 'ESPLENDOR': A LINGUAGEM CINEMATOGRÁFICA COMO POTÊNCIA DA AUDIODESCRIÇÃO
}

\author{
The poeticity of image in the movie 'Radiance' - the cinematographic language as \\ potency of audiodescription
}

\author{
La poeticidad de la imagen en la película 'Hacia la Luz' - El lenguaje \\ cinematográfico como potencia de la audiodescripción
}

Isabel Pitta Ribeiro Machado*

\begin{abstract}
Resumo
Este artigo foi inspirado no filme Esplendor, (Hicari; 2017), da diretora Naomi Kawase, devido à abordagem poética presente na linguagem de sua obra. À luz de autores da filosofia e do cinema, o artigo propõe uma reflexão sobre o conceito da audiodescrição no cinema e sua capacidade de desenvolver novos repertórios de imagem a partir de uma audiodescrição que contemple a linguagem cinematográfica. Assistir a um filme é usufruir da imagem que, ligada a outros elementos de linguagem de câmera, sonoros, dramáticos, cenográficos, espaciais e temporais, gera em cada espectador uma profusão dos sentidos. Estes elementos conjugados são a forma de representação simbólica da arte do cinema e, ao serem descritos em palavras, produzem novas relações simbólicas, fundamentais para a fruição da arte cinematográfica. Esta escrita não versa sobre o conceito e as formas de audiodescrição que a personagem do filme Esplendor, a audiodescritora Misako, utiliza em seu trabalho, tampouco sobre a audiodescrição do filme feita no Brasil, mas sim sobre uma audiodescrição que leve em consideração a poeticidade das imagens no momento de suas descrições.
\end{abstract}

PALAVRAS-CHAVE: Audiodescrição. Pessoa com Deficiência. Linguagem Cinematográfica

\begin{abstract}
This article has been inspired in the movie Radiance (Hicari;2017), from the director Naomi Kawase, because of the poetic approach present in the movie's language. In the light of authors of philosophy and movies, this article offers a reflexion about the concept of audiodescription inside cinema and its capacity of developing new repertoires of image from a audiodescription that contemplates cinematography language. To watch a movie is to use the image that, connected with others elements such as language of camera, sound, scenographic, spatial and temporal, creates in each spector a abundance of senses. These combined elements are the form of symbolic representation of the art of cinema and, by being described in words, generates new symbolic relations that are fundamental for the enjoyment of cinematographic arts. This writing does not speaks about the concept and the forms of audiodescription that the character of the movie Radiance, the audiodescriptor Misako, uses in her work; neither is it about the
\end{abstract}

\footnotetext{
* Mestre em Multimeios no Instituto de Artes da Unicamp. E-mail: multibell@gmail.com
} 
audiodescription made for the movie in Brasil. It is about though a audiodescription that takes in consideration the poetry of images in the moment of their descriptions.

KEYWORDS: Audiodescription. Visual Impairmants. Cinematic Language

\section{Resumen}

Este artículo fue inspirado en la película Hacia la Luz, (Hicari;2017), de la directora Naomi Kawase a causa del abordaje poético que figura en el lenguaje de su película. A la luz de autores de filosofía y de cine, el artículo propone un proceso de reflexión acerca del concepto de la audiodescripción en el cine y su capacidad de desarrollo de nuevos repertorios de imagen a partir de una audiodescripción que abarque el lenguaje cinematográfico. Ver una película es gozar de la imagen que, conectada a otros elementos del lenguaje de la cámara, sonoros, dramáticos, escenográficos, de espacio y temporales, genera en cada espectador una profusión de los sentidos. Eses elementos conjugados son la forma de representación simbólica del arte del cine $\mathrm{y}$, al describirlos en palabras producen nuevas relaciones simbólicas, fundamentales para el disfrute del arte cinematográfico. Esta escrita no se refiere al concepto ni a las formas de audiodescripción que el personaje de la película Hacia la Luz, la audiodescriptora Misako, utiliza en su trabajo, tampoco sobre la audiodescripción de la película hecha en Brasil, pero sobre una audiodescripción que lleve en conta la poeticidad de las imágenes en el momento de sus descripciones.

PALABRAS CLAVE: Audiodescripción. Personas con Discapacidad. Lenguaje Cinematográfico

Assistir a um filme é sentir uma profusão de sensações, é usufruir dos elementos de som e imagem, que constituem sua gramática. Estes elementos conjugados são a forma de representação simbólica da arte cinematográfica e, ao serem descritos em palavras, poderão contribuir para a formação do repertório imagético das pessoas com deficiência visual e para o desenvolvimento de novas relações simbólicas, tão fundamentais para a fruição da arte.

Diante de um filme, a experiência do olhar se reverbera no corpo e somente poderá ser apreendida pela pessoa com deficiência visual por meio do relato da experiência do olhar do audiodescritor, que, por sua vez, deve estudar a obra a ser audiodescrita. A descrição da linguagem do filme no roteiro de audiodescrição (AD) pode ser decisiva para que a pessoa entenda as óticas de representação, responsáveis pela fisionomia do objeto filmado e pelo sentido do filme.

No filme de Naomi Kawase, Esplendor (Hicari, no título original, e Radiance, em inglês), o olhar da jovem audiodescritora Misako (Ayame Misaki) para o fotógrafo Nakamori (Masatoshi Nagase) é de entrega, mas também de busca. O fotógrafo, que está perdendo a visão, ainda não aprendeu essa linguagem de entrega na qual as imagens são transformadas em palavras, pois sempre teve outros códigos de comunicação, assim como os videntes, que dependem do olhar para patentear certa verdade. A audiodescrição e tudo o que ela envolve será, para os dois, um grande desafio.

Se o olhar nos atrai e subtrai; se ele verte e se subverte no mais tênue abismo das superfícies da pele, da memória, das impressões, da metafísica, das coisas do mundo que estão além daquilo que a natureza pode dar conta de justificar ou mesmo explicar, 
onde está a certeza de uma imagem verdadeira? Na audiodescrição, também buscamos a objetividade da imagem, enquanto ela busca, em nós, a subjetividade.

Convido os leitores que conhecem ou não a audiodescrição para um passeio pelas coisas que compõem a parte invisível do olhar, aquela que está na mente de cada um, inclusive daqueles que não enxergam.

A expressão "não é o olhar que engana, mas o juízo que se faz das percepções que vêm por meio de todos os sentidos que possuímos"1 nos leva a refletir sobre tudo aquilo que nos acomete a partir da experiência sensorial. Dessa experiência, temos a percepção individual das coisas do mundo, o nosso olhar. Os sentidos são os condutores da singularidade das percepções e, a partir delas, construímos nosso conhecimento, temos sensações de desconforto ou prazer, formamos o gosto, tomamos partido e emitimos nossos juízos sobre as coisas do mundo, inclusive sobre as coisas belas e a estética, a relação do olhar com o objeto olhado, o prazer e o encantamento.

O filme Esplendor conta a experiência de uma audiodescritora, faz um recorte sobre a construção de um roteiro de audiodescrição (AD) para pessoas com deficiência visual. Uma possibilidade de roteiro da primeira sequência do filme é:

(29'- 45") Vista por trás, uma pessoa caminha de costas. Detalhe apenas de sua cabeça e ombros. A imagem a segue, descendo degraus pela lateral esquerda de uma sala de cinema, um pouco desfocada, onde à direita há uma série de cadeiras enfileiradas.

(52"- 1'04") A pessoa se senta. Close de seu rosto, um homem oriental de pele clara, cabelos pretos com a franja que cobre o olho esquerdo. Com semblante sério e a boca levemente arqueada para baixo, põe um fone de ouvido. (1'04')

A AD é um recurso de acessibilidade comunicacional, utilizado com o objetivo de ampliar o entendimento de pessoas com deficiência visual, intelectual, baixa visão, disléxicos e idosos com baixa acuidade visual, em quaisquer situações nas quais as informações visuais sejam fundamentais ou relevantes para sua compreensão, como, por exemplo, no cinema, no teatro, na dança, nos desfiles, nos shows, nos museus, nas exposições, nos passeios turísticos, entre outras experiências visuais nas quais corpo e espaço se comunicam, se complementam, se integram ou, por que não dizer, se desassociam.

A AD pode ser feita em imagens estáticas e em movimento e é considerada por Eliana Franco (doutora em Letras pela universidade KU Leven, na Bélgica) um modo de tradução audiovisual intersemiótico, no qual o signo visual é transposto para o signo verbal. No cinema, a AD é feita por meio de um audiodescritor que descreve as cenas, os ambientes, os personagens e suas expressões (sim, suas expressões), a linguagem corporal, as mudanças de tempo e espaço, a iluminação, as articulações de planos, sempre entre as falas do filme.

De acordo com o artigo "A linguagem cinematográfica de planos e movimentos", o cinema utiliza dois meios para estabelecer a comunicação: a imagem e o som. No que se refere à imagem, ela constrói sua comunicação de dois modos: pelo

\footnotetext{
${ }^{1}$ MACHADO, Isabel Pitta Ribeiro, em Leitura comentada da Carta sobre os cegos.

${ }^{2}$ A linguagem cinematográfica de planos e movimentos. Disponível em <http://educom.fundhas.org.br/pdf/enquadramentos_movimentos_de_camera.pdf>. Acesso em: 3 de jan. 2019.
} 
conteúdo da imagem e pela forma por meio da qual o captamos. O conteúdo da imagem em uma cena é responsável pelo sentido lógico, puro, do objeto, cenário ou pessoa. A forma, a maneira pela qual a cena é mostrada, é o que dá um sentido para ela e determina a carga dramática desse conteúdo: o lugar da câmera, o deslocamento realizado por ela, a maneira pela qual a ação é filmada, a escolha do ângulo, da distância, qual parte do cenário foi focado ou desfocado, o ritmo em que as cenas aparecem, entre outros detalhes/elementos, entretanto, nem sempre há tempo entre as falas do filme para todas essas descrições. Desse modo, aqui se instala um dos problemas da tradução visual, momento no qual o audiodescritor deverá escolher, a partir de seu olhar e de seu conhecimento da obra, o que e como a imagem escolhida deverá ser descrita.

Se a imagem no cinema constrói sua comunicação pela forma e pelo conteúdo, a audiodescrição no cinema também deve seguir os pressupostos da linguagem da arte a que se propõe descrever, para que se dê à pessoa que não enxerga a possibilidade da construção de uma memória dos artifícios da montagem do cinema.

Ismail Xavier, em "O discurso cinematográfico: a opacidade e a transparência", distingue algumas vertentes da tradição cinematográfica, entre elas algumas que pressupõem o cinema como transparente, isto é, um cinema que conta com o fato de que todas as pessoas já tenham interiorizadas em seu imaginário as formas que as imagens se articulam no intuito de dar um sentido ao filme, por meio dos planos, ângulos e movimentos sequenciais. Este fato justificaria, talvez, um tipo de audiodescrição que não mencione essa linguagem no roteiro de $\mathrm{AD}$, pois pressupõe que o espectador já a tenha introjetada. Desse modo, instala-se um debate muito pertinente para a reflexão sobre as formas de absorção e imaginação das imagens por parte dos cegos congênitos, visto que eles não têm a apreensão visual do mundo, a não ser por meio das descrições dos que veem. A propósito, o consultor de roteiros de $\mathrm{AD}$, Jean Bráz, cego congênito, traz em sua fala: "Por que a questão do visual, da linguagem cinematográfica no roteiro, é importante? Porque eu preciso entender e conseguir me comunicar com as outras pessoas, e eu não tenho contato só com pessoas que não enxergam, pelo contrário, meu maior contato é com pessoas que enxergam. E eu preciso compreender esse universo; eu preciso entender e saber como as coisas acontecem por meio de um sentido que eu não tenho. E como é que eu vou conseguir entender e compreender esse universo pra que eu consiga comentar um filme? (...) E quando eu digo 'comentar', eu preciso comentar com os mesmos elementos que uma pessoa que enxerga tem. Eu preciso usar dos elementos de posicionamento de câmera, porque como nós vimos no curso de cinema, a câmera é o olho do espectador. Então, se esse olho é a câmera que transmite essa sensação, é a câmera que dá essa ideia. Porque sem ela não seria cinema, seria uma radionovela... E como eu vou entender esse universo, se eu nunca enxerguei? Quem vai me passar isso de forma clara? Como vai chegar até mim essa noção? Ela precisa chegar de forma bem construída. Porque uma coisa é a descrição de uma imagem de um quadro, outra coisa é você, além de descrever, me dar elementos que eu não tenho, que vão me fazer entender isso. E você só vai conseguir me fazer entender isso, se você souber descrever com propriedade. E pra que você tenha propriedade, você (audiodescritor) tem que, no mínimo, entender do assunto que você está falando"

Também a consultora de roteiro, Emmanuelle Alkmin, cega desde os 6 meses de idade, afirma: "A gente não enxerga e a gente está diante de uma arte que é extremamente visual. A audiodescrição faz essa intersecção de mundos. E isso é muito 
sério. Como você faz essa intersecção? Como eu trago alguém que não enxerga, que falta exatamente o sentido que a arte prioritariamente usa para mostrar esse mundo do cinema? Nós estamos em um mundo no qual não temos a autonomia plena, ou quase nenhuma, para absorção, para a apreensão e para a percepção dessa arte. O que a maneira de filmar muda? Muda a abordagem, não só de conteúdo, mas a abordagem imagética pura. E como eu estabeleço a abordagem imagética pura? É entendendo a linguagem, entendendo um posicionamento de câmera, entendendo qual é o plano, qual é a tomada, o que a gente está querendo dizer com aquele foco daquela imagem. Eu não tenho como dizer que eu vi o filme ' $x$ ', sem que a audiodescrição traga pra mim 'Como eu vi', e o 'como eu vi' é a linguagem cinematográfica, é onde está a câmera. Se existe esse fascínio pra pessoa que enxerga, ou eu o apreendo, ou eu não vou ser fascinada pela arte do cinema".

As falas que Jean e Manu trazem da experiência do cinema não são tão diferentes daquelas que pessoas que enxergam poderiam trazer, pois se referem aos indivíduos (antes da deficiência), e são eles que buscam um entendimento maior da arte e de si mesmos. São buscas atreladas a valores simbólicos de representação, cuja tradução visual do cinema os ajudou a construir. A diferença é que, aí sim, tiveram a oportunidade de ver um filme a partir de uma audiodescrição que contemplasse a linguagem cinematográfica, como no exemplo da audiodescrição da sequência da escadaria de Odessa, no filme Encouraçado Potenkim, de S. Eisenstein, no qual a forma como os planos são articulados, hora de cima para baixo, hora de baixo para cima, é que dão o sentido de hierarquia, de luta de classe (sequência analisada e descrita em Machado, 2015, em dissertação de mestrado). A linguagem do cinema traz isso, novos lugares, espelhamentos, projeções, recusas e identificações, enfim, elementos para sua discussão.

No filme Esplendor, o fotógrafo, que um dia enxergara, passa a encontrar, dentro de sua condição, possibilidades de pensar as coisas do mundo a partir de novas percepções dos sentidos, e isto tem um valor imensurável para ele porque o salva. E salvaria qualquer vidente que pretendesse manter em sua vida o desejo de ver. $O$ conceito do olhar é um dos pressupostos para se pensar na audiodescrição no cinema e nas possibilidades de educação visual para a pessoa com deficiência visual. A imagem descrita é o resultado de uma montagem interna das percepções do descritor. Essa imagem traz palavras que levam a outras, como as do poeta Manoel de Barros:

(...) poesia é casada com as imagens formadas pelas palavras, porém, as imagens são, no fundo, palavras que nos faltaram. poesia: o vão que ocupa: poesia: ocupação da palavra pela imagem: ocupação da imagem pelo ser. No fundo, é a nós, leitores-seres, que alguma coisa é dita, retida, é guardada, calada ${ }^{3}$.

Ocupar-se das imagens para transformá-las em palavras e se ocupar da palavra para traduzir as imagens é o trabalho do audiodescritor. A descrição de uma fotografia, de um objeto ou de uma cena de um filme cria na imaginação do outro que ouve (e também daquele que vê) um espaço, uma interferência, uma intromissão que são rapidamente ocupados por outras ideias e imediatamente se transformam em imagens,

3BARROS, Manoel de. O Guardador de águas. São Paulo: Leya, 2010. p. 237. 
sensações, sentimentos, formas de memória e em novas palavras. A audiodescrição se ancora nas palavras e na imagem, cria ou forja uma ideia da imagem que se une ao conceito interno de cada um e, por isso também, resulta em uma diversidade enorme de intelecções.

No cinema, diferente do teatro, a descrição é uma possibilidade de ver as imagens a partir de um ponto de vista, o do personagem, o da câmera, que é também o da pessoa que filma. Essa questão está muito bem representada no filme Esplendor, na minutagem 1'30", onde há uma sequência de cenas de pessoas de diversas idades, carros, prédios, mostrados por diferentes ângulos e distâncias. Ao fundo, se ouvem duas trilhas sonoras que se sobrepõem: a trilha do som original do lugar, das vozes e dos ruídos da cidade e uma trilha musical de um piano. Uma terceira trilha sonora é inserida sobre tudo isso, a de uma voz feminina descrevendo as imagens conforme aparecem na tela. A beleza e a poesia dessa sequência, a meu ver, estão na maneira pela qual a diretora utilizou a linguagem cinematográfica na articulação dos planos. Entre tantas trocas de cenas, ela colocou, ocupando toda a tela, o close, a imagem bem de perto, dos olhos de uma jovem e, refletida neles, a rua a sua frente. Com essa montagem, Naomi Kawase disse, em dois segundos, que aquilo tudo estava sendo dito por meio da lente subjetiva do olhar. É por meio dessa linguagem que se dá o esplendor do cinema.

O momento da tradução dessas imagens em palavras é, em certa medida, o de uma transformação, de uma transferência, de uma indução, que são modos imprecisos (para nós que vemos e comparamos) e delatam a impossibilidade de uma tradução objetiva das imagens em palavras.

De acordo com Giovanni Boccara, na introdução ao conteúdo programático de sua disciplina "Epistemologia e Antropologia da comunicação visual - A escrita: o roteiro e suas correlações com a imagem cinematográfica", "tanto a palavra como a imagem técnica são descontinuidades que recuperam sua continuidade na construção de uma significação intencional quando são relacionadas na produção de um filme". Essa questão demonstra o quanto a construção do conhecimento por meio da audiodescrição no cinema é a busca de uma continuidade do entendimento, a partir da descontinuidade verborrágica e da descontinuidade abstrata das imagens. A escrita do roteiro de audiodescrição de um filme consiste em escolhas de imagens e formas de descrição.

Em Esplendor, as cenas de debate após a audiodescrição do filme, entre a audiodescritora e as pessoas com deficiência visual, nas quais discutem as formas de percepção da audiodescritora, suas escolhas e os diferentes modos de apreensão das imagens por meio de certas palavras demonstram a riqueza da tradução audiovisual.

Para Vilém Flusser ${ }^{5}$ (2011), escrever é uma sucessão de formas de rasgar imagens, além de ser um ato de fazer incisões, criar rupturas, e isso também é aquilo que o audiodescritor faz com as imagens do filme, no entanto, um espectador que ouve

\footnotetext{
4Disciplina DE-008-EB- Epistemologia e Antropologia da Comunicação Visual "A escrita: o roteiro e suas correlações com a imagem cinematográfica” (prof. E.G.Boccara), cursada por Machado, I.P.R. no programa de Pós-Graduação em Multimeios/IA-Unicamp/2014.

5 Vilém Flusser foi um filósofo e teórico da mídia nascido em 1920, em Praga. Seu mais conhecido livro, Filosofia da caixa preta foi publicado em mais de 15 países, mas boa parte do seu trabalho permanece desconhecido, inclusive do público brasileiro. Disponível em:

http://www.ihuonline.unisinos.br/index.php?option=com_content\&view=article $\&$ id $=4565 \&$ secao=399. Acesso em: 3 de jan. 2019.
} 
(com deficiência visual ou que escolheu permanecer de olhos fechados) não poderá conferir qual a medida dessas rupturas, e o audiodescritor deverá ter a responsabilidade de transformar aquelas imagens em palavras. É a palavra que deverá fazer com que o fluxo contínuo das imagens não pare na mente da pessoa cega.

Se para as pessoas que não enxergam os conceitos das coisas do mundo são ampliados a partir de seus sentidos e das descrições feitas pelos que veem, por meio de palavras (escritas ou lidas em braile ou ouvidas), talvez seja possível refletir, a partir da leitura de Flusser, sobre a construção do conhecimento, não apenas no sentido de investigar a maneira como as imagens se formam na mente do espectador cego, mas, no caso do cinema, no processo pelo qual o roteirista de cinema, por meio da escrita, rasga as imagens de seu imaginário transformando-as, reduzindo-as, traduzindo-as em textos para serem imaginados pelo diretor, que os transformarão em imagens de um filme para que o audiodescritor as transforme em palavras, para que então sejam imaginadas pelo espectador cego.

- Quantos rasgos, ranhuras, rasuras e fissuras existem nessa comunicação, nessa tradução intersemiótica?

De acordo com a teoria da escrita de Flusser, "roteiristas escorregam impetuosamente no precipício. São equilibristas em uma acrobacia literária, pois existe a questão do equilíbrio entre texto e imagem". 6

Do ponto de vista do audiodescritor (que se ancora nas imagens e nas palavras para dar possibilidades de enxergar ao espectador cego), a referida fala do autor remete ao trabalho do roteirista de audiodescrição, que sempre tem em mente o desejo de que as palavras escolhidas sejam adequadas o suficiente para a descrição das imagens. Apropriando-se dos termos de Flusser, se poderia dizer que "Roteiristas escorregam impetuosamente no precipício", mas que as imagens retransformadas em escrita pelo audiodescritor estão em meio a um abismo, suspensas por um desequilíbrio estático, para que "sejam vistas", naquele instante fugaz.

Em Flusser, as linhas do que está escrito não orientam os pensamentos apenas em sequência, mas se orientam ao receptor. Ultrapassam o ponto final e vão ao encontro do leitor (...). "O que está escrito vai além da orientação dos pensamentos internamente, mas se dirige aos outros, se voltando para o exterior (...)". "Escrever é um estado de tensão entre o movimento para dentro e o movimento para fora."

Esse conjunto de ideias do autor, concebidas para aqueles que enxergam, faz ainda mais sentido para os cegos congênitos, que nunca enxergaram, primeiro, porque tudo aquilo que é imaginado vem de uma abstração e, no cinema, as palavras ouvidas por meio da audiodescrição tomam outra proporção, pois têm uma função motora do imaginário; segundo por que a audiodescrição, sendo uma um tipo de tradução intersemiótica e uma fusão sonora denominada também de hibridismo sonoro ${ }^{7}$, leva esse leitor/ouvinte a entrar, assim como o escritor, ao "estado de tensão entre o

\footnotetext{
${ }^{6}$ Vilém Flusser, em Filosofia da caixa preta, cap. 17. São Paulo: Editora AnnaBlume, 2011. Retomado em A escrita - Há futuro para a escrita? São Paulo: Annablume, 2010.

7 "A audiodescrição como um hibridismo sonoro na obra de Peter Greenaway". Trabalho de Isabel. Pitta Ribeiro Machado, apresentado para a disciplina DE 010, Processos de Criação na Realização Cinematográfica e Videográfica. Mediações e Hibridismos na Arte Contemporânea. Novas Linguagens em Diálogos de Cinema e Pintura. Ministrada no Instituto de Artes da Unicamp pela professora Rosa Cohen. Cursada no Mestrado no $1^{\circ}$ semestre de 2013. Resumo do trabalho em Anexo 14.
} 
movimento para dentro e para fora", a partir do momento em que internaliza, ou seja, ouve de fora a descrição do visível, para então se encontrar lá dentro com sua representação, isto é, elaborar para imaginar certa imagem cinematográfica.

Se considerarmos que ser objetivo é manter um foco e o olhar é plural, seria possível uma tradução de imagens em palavras dar conta, objetivamente, do cinema?

De acordo com a memória de cada um, temos um objeto e, a partir do juízo que fazemos de nossas percepções, vindas por meio dos sentidos, incluindo as sensações, temos um olhar e, então, percebemos que a imagem que vemos não está nem no objeto em si nem em nosso olhar, mas em nossa imaginação, que, de acordo com o professor Milton José de Almeida, está em um lugar que pode ser chamado de "entremundo". Este é um lugar no qual a escolha transita, e essa imagem poderá ou não ser revelada à pessoa cega na audiodescrição. Nesse labirinto, nessa dificuldade de, por meio das percepções, revelar objetivamente aquilo que os olhos viram, é que o audiodescritor deve trabalhar.

Para compor a reflexão sobre a forma de descrição de imagens, trago os autores Eduardo Nunes e Helder Mendoza (aos quais me aterei mais adiante), pois versam sobre a questão da poética no cinema como forma de representação simbólica da arte cinematográfica e, por isso, a meu ver, devem estar presentes de alguma forma na elaboração das descrições do roteiro de $\mathrm{AD}$, visto que podem contribuir para o aumento do repertório imagético, para a formação de conceitos e consequentemente para o desenvolvimento de novas relações simbólicas para as pessoas com deficiência visual, gerando assim novas sensações e maior fruição dessa arte.

Ainda no intuito de uma argumentação a favor do conhecimento da linguagem cinematográfica no processo de educação visual das pessoas com deficiência visual, é de suma importância o pensamento do teórico e crítico de cinema francês André Bazin ${ }^{8}$, pois, para o autor, a evolução do espectador de cinema está vinculada a uma experiência individual do olhar e à experiência do cinema, que significa ver e reparar nos planos e nos movimentos de câmera.

- E como essa linguagem se concretiza na experiência do olhar da pessoa com deficiência visual? Ela simplesmente não se concretiza, se não houver um roteiro de audiodescrição que a descreva. Desse modo, na perspectiva de análise de Bazin, pode-se dizer que, em detrimento da noção de como as imagens se constituem no cinema (noção essa que se constrói a partir de referências que forneçam parâmetros de comparação entre imagens reais e reconstituídas pela montagem), o espectador com deficiência visual que não tiver acesso à linguagem fílmica terá de esperar um tempo para encontrar seu lugar como espectador crítico do cinema.

Considerando o que foi dito, segue o pensamento de André Bazin que concebe o cinema como uma linguagem que possibilita falar da realidade e da imaginação: "O importante é que possamos dizer, ao mesmo tempo, que a matéria-prima do filme é autêntica e que, no entanto, "é cinema". Assim, a tela reproduz o fluxo e refluxo de nossa imaginação, que se nutre da realidade à qual ela projeta se substituir; a fábula nasce da experiência que ela transcende".

\footnotetext{
${ }^{8}$ BAZIN, A. O que é cinema - ensaios. 2011, p. 60. Disponível em: $<$ https://cineartesantoamaro.files.wordpress.com/2011/05/o-cinema-ensaios-andre-bazin.pdf >. Acesso em: 3 de jan. 2019.
} 
No que tange à audiodescrição como uma tradução audiovisual das imagens, ao pensarmos em algumas cenas do filme Esplendor, poderíamos pensar, antes que elas decantassem em nossa memória, no conceito do olhar. De forma intensa, poderíamos expandir esse olhar e lembrarmos, por exemplo, do efeito do nosso corpo ao ver o beijo que Misako, inesperadamente, dá no fotógrafo, ou na maneira como a diretora contrapõe os rostos de Misako e do fotógrafo, no momento em que ela descreve as cores refletidas pelo prisma em suas mãos. Os closes delatam a intensidade dos desejos silenciosos quando ele diz a ela que a descrição estava linda. Pense em como descrever essas cenas. O olhar é afetado por estímulos, portanto, plural, assim como suas formas de descrição.

Na perspectiva do olhar de Tarkovsky (que jamais conheceu a audiodescrição), audiodescrever ou, como ele diria, esculpir as imagens artísticas do cinema seria uma possibilidade de renovação do audiodescritor, seria ganhar de presente o tempo para olhar de novo, uma busca incansável da palavra adequada para se descrever da melhor forma possível uma imagem pressuposta como verdadeira. Em princípio, vale se perguntar: qual imagem é a verdadeira?

Retomando os autores citados, Eduardo Nunes e Helder Mendoza, na composição de uma reflexão sobre a forma de descrição de imagens, Nunes (2014) em seu artigo "A linguagem secreta", refere-se à ideia de verdade citando que Giambattista Vico avança da ideia da verdade para a ideia de uma verdade criada que seria a transformação das coisas para a sua própria compreensão: "uma verdade poética". Segundo o autor, a verdade poética, diferente da ideia de verdade como a conhecemos, seria a visão do artista criador sobre a vida.

A propósito da questão poética no cinema, Mendoza (2006), em sua dissertação de mestrado "A imagem poética", afirma que é fundamental num estudo sobre a influência da linguagem poética no cinema, fazer uma investigação sobre a analogia entre a poesia das imagens e a cinematografia poética e que, neste sentido, se deve ressaltar a importância do conceito de imagem para então se definir o que pode ser considerado poético no cinema. Segundo o autor,

sempre aliada a elementos sonoros, dramáticos cenográficos, espaciais e temporais, a imagem constitui um dos componentes de maior profusão de sentidos e simbologias que o sistema cinematográfico dispõe. Assim sendo, para compreendermos a questão da imagem poética no cinema, precisamos inicialmente buscar definir quais seriam suas ramificações no âmbito da poeticidade e assim, posteriormente, identificar suas impressões no cinema (MENDOZA, 2006, p. 13).

Ele afirma ainda que

a imagem é um fenômeno de apreensão da imaginação do artista e da expressão de um momento, talvez de um instante, que se fixa no infinito de nossa memória" (...) "É amplo o debate sobre a dicotomia entre ilusão e realidade quando se busca uma definição sobre o conceito de imagem" (...) "o que podemos dizer, de fato, é que no âmbito da poeticidade a imagem é representada como a entidade de recriação do que há de peculiar e único no mundo, ou seja, é através da imagem poética que podemos perceber a

\footnotetext{
${ }^{9}$ Helder Quiroga Mendoza em Cinema e Poesia - uma relação intersemiótica em Akira Kurosawa Dissertação de Mestrado - Faculdade de Comunicação da Universidade de Brasília. 2006. p. 13
} 
diversidade de relações possíveis presentes no inequívoco mundano de maneira inusitada. (...) À capacidade de captação dos sentidos provenientes da imagem, denominamos percepção artística, ou seja, aptidão de apreender, através da sensibilidade, a gama de significados que podem ser extraídos de determinada ação ou objeto". (MENDOZA, 2006, p. 13).

Citando o filósofo Gastón Bachelard, Mendoza diz que a imagem poética é um tipo de abstração ou impulso, compreendido de maneira efêmera e fugaz que, por meio da expressão artística do poeta, busca materialidade na poesia.

As considerações de Mendoza são importantes para a reflexão sobre a audiodescrição no cinema, no sentido de que, quando estamos assistindo a um filme, estamos usufruindo da imagem que, ligada a outros elementos de linguagem de câmera, sonoros, dramáticos, cenográficos, espaciais e temporais gera, em cada espectador, uma profusão dos sentidos.

No filme Esplendor, há uma cena que revoluciona os sentidos, quando Misako e Nakamori, o fotógrafo, vão ao fim da tarde, ver o por do sol. Numa sequência de closes, em meio ao sol avermelhado que resplandece em seus rostos, ela se pergunta como segurar aquela luz esplendorosa; ele então conta que seu coração estava chiando e, às vezes, ouvia o chiado do coração dela. Num ímpeto, ele acaricia sua câmera fotográfica e a arremessa longe. Ela o olha assustada, de olhos bem abertos, e pergunta por quê. Sem resposta, ela segura o rosto dele e o beija, sob a luz dourada do sol.

Esses elementos conjugados são a forma de representação simbólica da arte do cinema e, ao serem descritos, produzem novas relações simbólicas, fundamentais, como afirmado, para a fruição da arte cinematográfica.

Se a imagem é um fenômeno de apreensão da imaginação do artista e de sua expressão, ou se preferirmos, da materialização do instante fugaz dessa apreensão, seja na arte pictórica, cinematográfica ou literária, no âmbito da poeticidade, a imagem é representada como "recriação", portanto, imagem poética. Por isso, o cinema, sendo uma linguagem, é revelado pela audiodescrição nunca na medida exata, mas possível.

Nunes (2014), ao falar sobre a verdade poética, cita Tarkovski e afirma que o autor desenvolve o conceito de imagem artística por entender esta verdade como necessária para a criação de um cinema como arte.

Considerando-se a verdade poética de Vico e a imagem artística de Tarkovski, reafirma-se a possibilidade da audiodescrição ser considerada também uma possibilidade artística, pois a AD se utiliza da subjetividade do olhar para revelar a verdade da imagem, seja ela uma imagem artística ou uma verdade poética.

Tarkovski afirma ser impossível fazer com que o conceito de "imagem artística" seja expresso de uma forma precisa, de fácil compreensão. Diz ainda que, a imagem avança para o infinito e nos leva ao absoluto. Para o autor, o que denominamos como "ideia" da imagem, em sua multiplicidade de significados, não poderia, pela própria natureza das coisas, ser posto em palavras.

A fala do Tarkovski impacta o audiodescritor, pois sugere que descrever imagens vai muito além de descrever apenas o que é visto. O autor coloca em cheque a própria ideia do que é visto e, sendo assim, o audiodescritor se sentirá provocado. Contudo, seu pensamento nos faz producentes porque instiga a mais uma vez pensar e a buscar uma ordem ideal também nas palavras e, para isso, tem-se que investigar (nas palavras do autor), "a natureza das coisas". 
Sendo assim, a audiodescrição continuará sempre sua busca pelas “incertas” palavras, na vontade de descrever as imagens artísticas do cinema de um determinado autor para que cada pessoa que não enxerga possa encontrar, por si, a relação entre a forma exata de expressão do mundo do artista e de seu mundo ideal, o que lhe permitirá criar uma nova dimensão de um suposto mundo real.

O livro Esculpir o tempo ${ }^{10}$, de A. Tarkovski, contém uma contestação visceral de alguns conceitos pressupostos e leva o leitor a naturalmente rever seus próprios conceitos, tarefa imprescindível para aqueles que pretendem descrever as coisas visíveis do mundo.

\begin{abstract}
O autor diz que 'a imagem é indivisível e inapreensível e depende da nossa consciência e do mundo real que tenta corporificar. Se o mundo for impenetrável, a imagem também o será. (...) Não podemos perceber o universo em sua totalidade, mas a imagem poética é capaz de exprimir essa totalidade. A imagem é uma impressão da verdade, um vislumbre da verdade que nos é permitido em nossa cegueira. (...).
\end{abstract}

A ideia do autor, aplicada à audiodescrição, poderia levar, num primeiro momento, a um entendimento de que a descrição clara e objetiva da imagem seria algo inalcançável, mas o que está dito é que a pluralidade do olhar do artista constrói uma imagem poética revelada na filmagem que, por sua vez, será vista por outro, já transformada. Sim, é possível ser claro e objetivo ao fazer uma descrição, porém, a percepção está em outra esfera, a da subjetividade. Das lacunas da percepção, surge então a questão simbólica da cegueira, relativa às coisas vistas, porém, não percebidas.

- E de que maneira se poderia audiodescrever algo que não foi percebido? $\mathrm{E}$ de que maneira as pessoas com deficiência visual, por exemplo, podem incorporar tais conceitos se nós, tradutores, não temos o hábito de pensar na acessibilidade das imagens artísticas? Numa certa perspectiva, poderemos correr o risco de deixar o mundo ficar impenetrável para as pessoas cegas, diante da falta de acesso à poeticidade da imagem.

Por isso, é muito necessário, para quem descreve, o estudo da obra e da linguagem que a representa, para que se possa se apropriar do conhecimento, aguçar as percepções dos sentidos e encontrar as palavras adequadas para representá-la.

\title{
CONSIDERAÇÕES FINAIS
}

O cinema, para Tarkovski, não é um mero registro natural do objeto, mas a capacidade de observação do artista, que, a partir da sua ótica de representação, oferece uma nova imagem artística ou poética. Por isso, a sua fala "A imagem é indivisível e inapreensivel e depende da nossa consciência e do mundo real que tenta corporificar. Se o mundo for impenetrável, a imagem também o será" traz ressonâncias em meu trabalho com a audiodescrição. Desejo, portanto, que ao fim desta escrita, no imaginário dos diversos leitores, tenham se desenhado infinitas possibilidades de apreensão do real que contribuam para a construção de uma memória dos artifícios das imagens no cinema. E que as formas de perceber o outro e a si mesmo, descrever imagens e imaginá-las sejam tantas, a ponto de jamais deixarmos o mundo se tornar impenetrável. Em Esplendor, a audiodescritora e o fotógrafo encontraram um modo de se olhar,

${ }^{10}$ TARKOVSKI, Andrei em Esculpir o templo. Ed.Martins Fontes, 2010, p.123 
tiraram os véus que cobriam o tato e os beijos. Confundiram-se até calarem seus olhos e não precisarem mais deles. Isto é poesia, possível a partir da poeticidade da imagem.

\section{REFERÊNCIAS}

MACHADO, I. P. R. A parte invisível do olhar-audiodescrição no cinema: a constituição das imagens por meio das palavras - uma possibilidade de educação visual para a pessoa com deficiência visual no cinema. The invisible side of the eye : audiodescription in the movies : the creation of images through words - a possibility of visual education for visually impaired person in the cinema. 2015. $226 \mathrm{f}$. Dissertação (Mestrado em Multimeios). Programa de Mestrado em Multimeios do Instituto de Artes da Unicamp. Campinas. 2015. Disponível em: <http://repositorio.unicamp.br/bitstream/REPOSIP/285178/1/Machado_IsabelPittaRibei ro_M.pdf>. Acesso em: 3 jun. 2019.

Recebido em: 12/10/2019

Aprovado em: 04/12/2019 